\title{
The wandering spleen: an unusual case of thrombocytopenia
}

\author{
This article was published in the following Dove Press journal: \\ Journal of Blood Medicine \\ 6 December 201I \\ Number of times this article has been viewed
}

\section{Curtis Mirkes \\ George Nguyen \\ Christian Cable}

Department of Internal Medicine, Division of Hematology and Oncology, Texas A\&M Health Science Center, College of Medicine, Scott \& White Healthcare, Temple, TX, USA
Correspondence: Curtis Mirkes Scott \& White Hospital, 240I South 31st Street, Temple, Texas 76508, USA

Tel +l 2547248797

Fax + I 2547244079

Email crmirkes@swmail.sw.org
Abstract: Thrombocytopenia is a common laboratory finding in current medical practices. The workup of thrombocytopenia can be challenging with numerous causes that can be included in the differential diagnosis. Thrombocytopenia can be due to bone marrow hypoproliferation, peripheral destruction, or sequestration. This paper presents a case of isolated thrombocytopenia in a young female and discusses the causes of thrombocytopenia.

Keywords: peripheral sequestration, enlarged spleen, congenital, hypertension, hypersplenism, diaphragmatic hernia

\section{Introduction}

The workup of isolated thrombocytopenia is common in hematology practice and is often conceptually divided into causes of bone marrow hypoproliferation or peripheral destruction or sequestration. Anatomic considerations for thrombocytopenia are typically not evaluated due to the low incidence of the subsequent cause of thrombocytopenia. Congenital diaphragmatic hernias can be a cause of low platelet counts. This paper presents an unusual case of isolated thrombocytopenia: the wandering spleen.

\section{Case report}

A previously healthy 21-year-old woman, 16 weeks pregnant with her first child, presented to the hospital with nausea, vomiting, and right flank pain. She was diagnosed with pyelonephritis, and treated with appropriate antibiotics. When she was 24 weeks pregnant she presented in consultation for evaluation of thrombocytopenia 8 weeks following initial hospitalization. She took only prenatal vitamins and did not drink alcohol or use nonprescribed medications or illicit drugs. Her personal and family history was unremarkable for any bleeding or clotting disorders. Physical examination demonstrated normal vital signs, normal cardiac exam, peristaltic sounds in the left chest, and a gravid uterus which precluded full examination. There were no petechiae or other signs of bleeding. At the time of consultation, platelet count was $76,000 / \mathrm{L}$ (150-450/L) with a mean platelet volume (MPV) of $12.3 \mathrm{fL}$ (7.4-12.0 fL), hemoglobin was $10.1 \mathrm{mg} / \mathrm{dL}(12.0-16.0 \mathrm{mg} / \mathrm{L})$, and white blood cell count was 4400/L (4.8-10.8/L) with a normal differential. Peripheral blood smear review confirmed thrombocytopenia, excluded microangiopathic changes, and revealed red cell morphology consistent with iron deficiency. Folate and B12 were normal. Serologic testing for viral hepatitis and human immunodeficiency virus were negative; Helicobacter pylori was not tested for 
during this hospitalization. Liver transaminases and bilirubin were normal. A bone marrow examination demonstrated iron deficiency, megakaryocytic hyperplasia, and no evidence of dysplasia or megaloblastic change. Cytogenetic studies were normal with 46, XX. As part of the workup during the previous illness a chest X-ray was obtained (Figure 1), which demonstrated a cystic appearance to much of the left lung and elevation of the left hemidiaphragm. A computed tomography scan (Figure 2) with abdominal shielding was obtained and revealed herniation of abdominal contents into the left hemithorax. The spleen was intrathoracic and its craniocaudal dimension was $17 \mathrm{~cm}$. The spleen was of uniform density without any focal lesions. One month after an uncomplicated delivery, the platelet count remained 73,000/L with an MPV of $12.4 \mathrm{fL}$. One year after delivery, a platelet count of $80,000 / \mathrm{L}$ with an MPV of $12.1 \mathrm{fL}$ was obtained. The diagnosis of thrombocytopenia due to peripheral sequestration in a wandering spleen was made.

\section{Discussion}

Thrombocytopenia can be classified according to either decreased production with bone marrow hypoproliferation or increased destruction. Common causes of thrombocytopenia in young female patients include primary immune thrombocytopenia, bone marrow suppression by infection, medication effects, and gestational thrombocytopenia. ${ }^{1}$ A list of possible etiologies is included in Table 1.

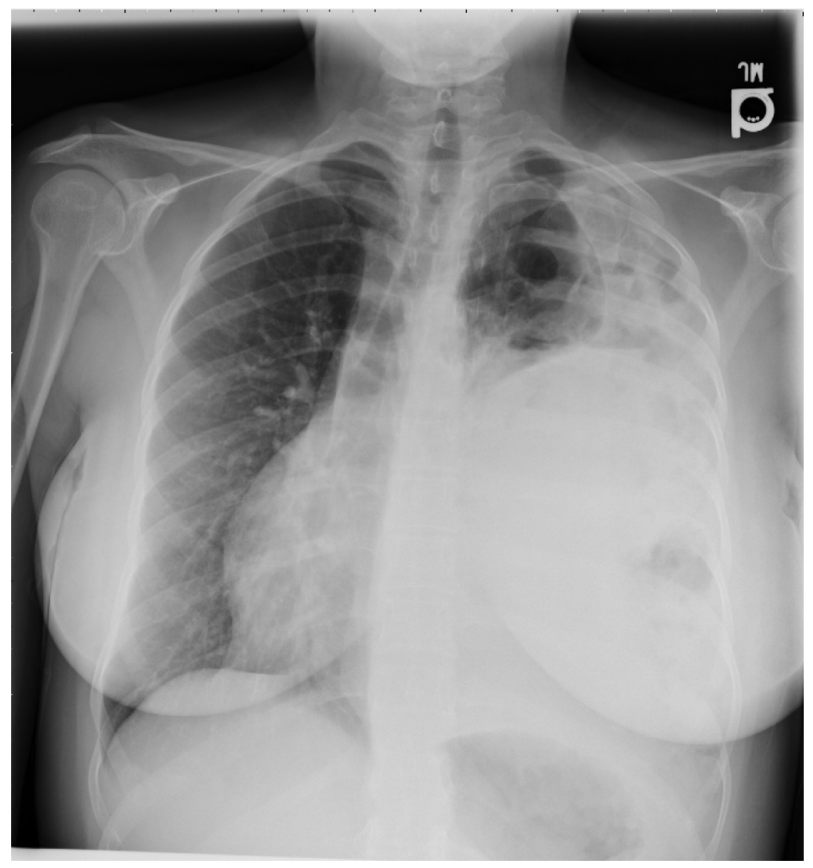

Figure I Cystic appearance to left lung with elevated hemidiaphragm.

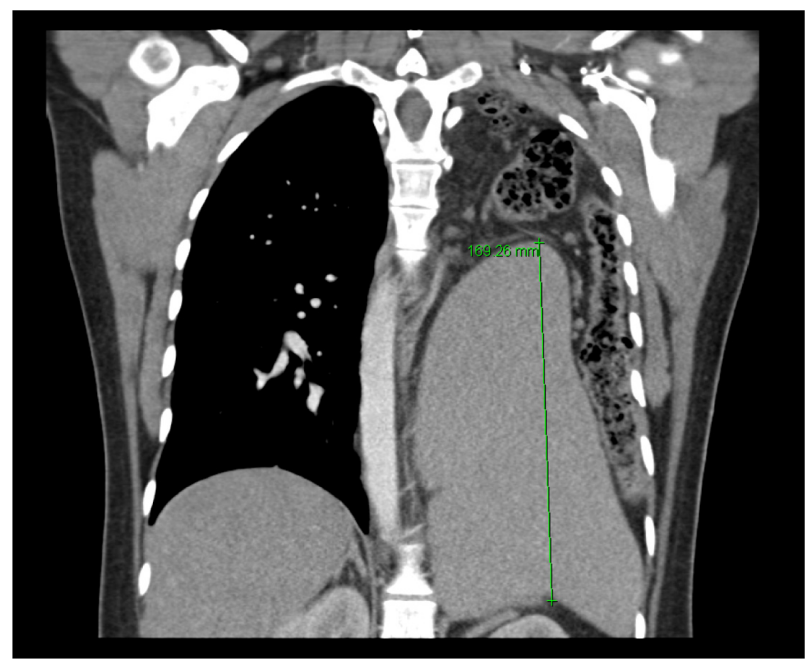

Figure 2 Abdominal contents including bowel and massively enlarged spleen.

Bone marrow suppression and primary immune thrombocytopenia are typically accompanied by a normal sized spleen. Hypersplenism as a cause of thrombocytopenia may reflect portal hypertension from cirrhosis, collagen vascular disease, or rarely primary neoplasm of the spleen. Gestational thrombocytopenia resolves after delivery by definition.

Although rarely considered, anatomical causes of thrombocytopenia do exist. Congenital diaphragmatic hernias are due to a defect in the diaphragm, either posterolateral (Bochdalek hernia), anterior retrosternal or peristernal (Morgagni hernia), or, rarely, central. The Bochdalek type of diaphragmatic hernia is the most common, but all diaphragmatic hernias can allow for abdominal contents, including bowel, viscera, and even organs such as the spleen, to herniate into the chest and impede lung formation resulting in hypoplasia. ${ }^{2}$ The spleen is normally prevented from cephalad migration by the diaphragm. The spleen is usually fixed in its position in the left upper abdominal quadrant through the splenic pedicle formed by the splenorenal and gastrosplenic ligaments and contains the splenic artery and vein and the tail of the pancreas. ${ }^{3}$ Asymptomatic prevalence of Bochdalek-type hernias in the general population may be as high as $0.17 \% 0^{4,5}$ Diaphragmatic hernias have also been seen as a result from penetrative or blunt trauma to the chest or abdomen; approximately 100 cases of Bochdalek hernias in adulthood have been reported. ${ }^{6}$

The proposed mechanism for splenic enlargement in this case is as a result of torsion or compression of the splenic pedicle with impairment of venous outflow and resultant splenic congestion and enlargement. ${ }^{3}$ An ectopic abdominal placement of the spleen, or "wandering spleen," is caused 
Table I Causes of thrombocytopenia

\begin{tabular}{ll}
\hline Decreased production & Increased destruction \\
\hline $\begin{array}{l}\text { Bone marrow suppression } \\
\text { Medication induced }\end{array}$ & Pregnancy \\
$\begin{array}{l}\text { Infection (viral, bacterial, fungal) } \\
\text { Malignancy }\end{array}$ & Preeclampsia (HELLP) \\
Nutritional & \\
Congenital & Impersplenism \\
Bernard-Soulier syndrome & Primary immune thrombocytopenia \\
Wiskott-Aldrich syndrome & Lupus \\
Fanconi syndrome & Medication induced \\
Thrombocytopenia-absent radius syndrome & \\
& Nonimascular disease \\
& Thrombotic thrombocytopenia purpura \\
\hline
\end{tabular}

Abbreviation: HELLP, hemolytic anemia, elevated liver enzymes, and low platelet count.

by an elongated splenic vascular pedicle and can produce splenomegaly by a similar mechanism.

Hypersplenism from splenic sequestration resulting in thrombocytopenia seen as a complication of congenital diaphragmatic hernia is a rare finding. Typically, congenital diaphragmatic hernias are detected at or near the time of delivery and most presentations involve respiratory distress secondary to a hypoplastic lung. A Bochdalek-type hernia later in life, similar to the present case, has rarely presented, where strangulation of her spleen within the left hemithorax led to the development of left-sided portal hypertension, hypersplenism, and thrombocytopenia. ${ }^{6}$

\section{Conclusion}

The wandering spleen is an unusual congenital anatomic cause of thrombocytopenia and may be explained by the mechanism of peripheral sequestration in an enlarged spleen.

\section{Disclosure}

The authors report no conflicts of interest in this work.

\section{References}

1. Provan D, Stasi R, Newland AC, et al. International consensus report on the investigation and management of primary immune thrombocytopenia Blood. 2010;115(2):168-186.

2. Bohn D. Congenital diaphragmatic hernia. Am J Respir Crit Care Med. 2002;166(7):911-915.

3. Moll S, Igelhart JD, Ortel TL. Thrombocytopenia in association with a wandering spleen. Am J Hematol. 1996;53(4):259-263.

4. Buranda L, Larrucea I, Ramos F, Muñoz C, Sánchez A, Fernández I. Bochdalek's hernia in adults. J Clin Gastroenterol. 2001;32(2): 155-157.

5. Mullins ME, Stein J, Saini SS, Mueller PR. Prevalence of incidental Bochdalek's hernia in a large adult population. AJR Am J Roentgenol. 2001;177(2):363-366.

6. Kennedy R, Donaghy A, Ahmad J, McManus K, Clements WD. Portal hypertension and hypersplenism in a patient with a Bochdalek hernia: a case report. Ir J Med Sci. 2009;178(1):111-113.
Journal of Blood Medicine

\section{Publish your work in this journal}

The Journal of Blood Medicine is an international, peer-reviewed, open access, online journal publishing laboratory, experimental and clinical aspects of all topics pertaining to blood based medicine including but not limited to: Transfusion Medicine; Blood collection, Donor issues, Transmittable diseases, and Blood banking logistics; Immunohematology; Artificial and alternative

\section{Dovepress}

blood based therapeutics; Hematology; Biotechnology/nanotechnology of blood related medicine; Legal aspects of blood medicine; Historical perspectives. The manuscript management system is completely online and includes a very quick and fair peer-review system. Visit http://www.dovepress.com/ testimonials.php to read real quotes from published authors. 